\title{
Faktor yang Berhubungan dengan Deteksi Dini Kanker Serviks Metode IVA di Puskesmas Kota Padang
}

\author{
Miftahil Fauza ${ }^{*}$, Aprianti ${ }^{*}$, Azrimaidaliza*) \\ ${ }^{*}$ Fakultas Kesehatan Masyarakat Universitas Andalas \\ Korespondensi: aprianty17@gmail.com
}

\begin{abstract}
Background: The prevalence of cervical cancer in West Sumatra was 0.9 per 1,000 population in 2013. This data exceeds Indonesia's prevalence of 0.8 per 1,000 population. Lack of participation in early detection of cervical cancer through IVA test are as indirect causes of the high prevalence of cervical cancer. This study aims to determine the factors influenced to women's practice on IVA test at the Padang City Health Center in 2018.

Method: This research is an explanatory research with a cross-sectional approach, conducted from February to October 2018. The population of this study were fertile age women who visited Alai Health Center and Pegambiran Health Center with size sample of 110 respondents. Consecutive sampling method was employed to select the respondent. Data collection was conducted by interview using a questionnaire. Data were analyzed by ChiSquare statistical test and logistic regression with a confidence level of $95 \%$.

Results: The results of the study showed that $60 \%$ of respondents had never detected IVA test. The results of the statistical test showed that there was a significant relationship between the level of knowledge with $p$ value 0,000, attitude with $p$ value 0.041, access to information with $p$ value 0,000 and husband support with $p$ value 0,000 and the IVA test. The results of multivariate analysis showed that the most dominant variables affected the participation of women in cancer early detection through IVA tests, was husband's support with p value 0,000 and Odds Ratio 46,693, which means respondents who supported by husbands were likely to do IVA test 46 times compared to those not supported. Therefore the dissemination of information was not only provided to women but also men including husbands in order to motivate women for IVA test.
\end{abstract}

Keywords: Cervical cancer, IVA test, knowledge, attitude, fertile age women, husband support

\begin{abstract}
ABSTRAK
Latar Belakang: Pada tahun 2013 prevalensi kanker serviks di Sumatera Barat adalah 0,9 per 1.000 penduduk. Data ini melebihi prevalensi Indonesia 0,8 per 1.000 penduduk. Kurangnya pengetahuan masyarakat mengenai kanker serviks dan cara deteksi dininya merupakan faktor penyebab tidak langsung tingginya prevalensi kanker serviks. Penelitian ini bertujuan untuk mengetahui faktor-faktor yang berhubungan dengan partisipasi wanita usia subur dalam tes IVA di Puskesmas Kota Padang tahun 2018.
\end{abstract}

Metode: Penelitian ini merupakan riset eksplanatori dengan pendekatan Cross-sectional, dilakukan dari bulan Februari sampai Oktober 2018. Populasi penelitian ini adalah wanita usia subur yang mengunjungi Puskesmas Alai dan Puskesmas Pegambiran dengan jumlah sampel sebanyak 110 responden. Metode pengambilan sampel menggunakan metode consecutive sampling. Pengumpulan data dengan wawancara menggunakan kuesioner. Data dianalisis dengan uji statistik Chi-Square dan regresi logistik dengan tingkat kepercayaan $95 \%$.

Hasil: Hasil penelitian menunjukkan bahwa $60 \%$ responden belum pernah melakukan deteksi tes IVA. Hasil uji statistik menunjukkan ada hubungan yang signifikan antara tingkat 
pengetahuan dengan $p$ value 0,000 , sikap dengan $p$ value 0,041 , akses informasi dengan $p$ value 0,000 dan dukungan suami dengan $p$ value 0,000 dengan tes IVA. Hasil analisis multivariat menunjukkan bahwa variabel yang paling dominan mempengaruhi partisipasi wanita dalam deteksi dini kanker servis melalui tes IVA, yaitu dukungan suami dengan $p$ value 0,000 dan Odds Ratio 46,693 yang artinya responden yang didukung suami memungkinkan melakukan tes IVA sebesar 46 kali dibanding dengan yang tidak didukung. Oleh karena itu penyebaran informasi tidak saja diberikan kepada para wanita usia subur tetapi juga kepada para pria termasuk suami agar dapat ikut memotivasi para wanita untuk tes IVA.

Kata Kunci: Kanker serviks, tes IVA, pengetahuan, sikap, wanita usia subur, dukungan suami

\section{PENDAHULUAN}

Kanker serviks yang menyerang daerah leher rahim merupakan penyebab kematian tertinggi kedua pada wanita di dunia setelah penyakit kanker payudara dan merupakan penyebab utama kematian wanita di negara berkembang. ${ }^{(1)}$ Data dari Global Burden Cancer (GLOBOCAN), International Agency for Research on Cancer (IARC) menunjukkan pada tahun 2012 insidens kanker serviks di seluruh dunia sebesar 16 per 100.000 penduduk. Negara dengan angka penderita kanker serviks tertinggi yaitu Malawi dengan prevalensi sebanyak 75 per 100.000 penduduk, disusul oleh Mozambik dan Komoro. Berdasarkan data dari World Health Organization (WHO) pada tahun 2014 terdapat lebih dari 528.000 kasus baru dan 266.000 kasus kematian di seluruh dunia akibat kanker serviks pada wanita dengan usia 15-44 tahun ${ }^{(2)}$

Kanker serviks merupakan salah satu masalah utama kesehatan reproduksi pada perempuan di Indonesia. Menurut data dari
Kementerian Kesehatan Republik Indonesia (Kemenkes RI) pada tahun 2013, kejadian kanker serviks di Indonesia sebesar $0,8 \%$. Provinsi yang memiliki estimasi jumlah penderita kanker serviks terbesar adalah Provinsi Jawa Timur dengan estimasi 21.313 kasus. Sumatera Barat merupakan provinsi ke- 8 dengan estimasi jumlah kasus terbanyak di Indonesia yaitu sebesar 2.285 kasus. $^{(3)}$ Menurut data dari Riset Kesehatan Dasar (Riskesdas) tahun 2013 prevalensi kanker serviks di Sumatera Barat sebesar 170 per 100.000 penduduk. Menurut data dari Yayasan Kanker Indonesia (YKI) pada tahun 2007 Kota Padang merupakan penyumbang utama sebagai daerah dengan angka kejadian kanker serviks terbanyak dengan jumlah 107 kasus di provinsi Sumatera Barat. ${ }^{(4)}$

Kanker serviks dapat diantisipasi dengan melakukan deteksi dini. Beberapa deteksi dini yang bisa digunakan untuk mengetahui keberadaan kanker serviks adalah Pap Smear, Pap net, servikografi, 
tes inspeksi visual asam asetat (IVA), tes high-risk type (HPV), kolposkopi, dan sitologi berbasis cairan. ${ }^{(5)}$ Dari beberapa macam metode dalam deteksi dini kanker serviks, tes IVA menjadi metode yang saat ini menjadi program pemerintah di seluruh puskesmas di Indonesia, yaitu dengan gerakan pencegahan dan deteksi dini kanker pada perempuan Indonesia. Kegiatan ini merupakan bagian dalam mewujudkan masyarakat hidup sehat dan berkualitas, hal ini sesuai dengan tercapainya Nawacita kelima yaitu meningkatkan kualitas hidup manusia. Pemeriksaan IVA merupakan program yang tercantum dalam Keputusan Menteri Kesehatan Republik Indonesia No. 796/MENKES/SK/VII/2010 tentang pedoman teknis pengendalian kanker serviks dan payudara. ${ }^{(6)}$

Berdasarkan data dari Dinas Kesehatan Kota Padang pada tahun 2017, diantara 22 Puskesmas yang ada di Kota Padang, Puskesmas Alai adalah salah satu puskesmas dengan angka cakupan deteksi dini kanker serviks yang tinggi dengan persentase $48,64 \%$, namun angka ini masih belum mencapai target nasional yang menetapkan targetan $50 \%$ WUS melakukan deteksi dini kanker serviks metode IVA .(4) Sedangkan Puskesmas yang memiliki angka cakupan deteksi dini kanker serviks metode IVA yang rendah adalah Puskesmas Pegambiran dengan persentase pencapaian $6,77 \%$. Berdasarkan studi pendahuluan, melalui wawancara dengan pemegang program IVA diketahui masih belum meluasnya penyebaran informasi melalui promosi kesehatan tentang tes IVA sehingga banyak WUS ragu untuk ikut berpartisipasi tes IVA. Salah satu kendala pelaksanaan tes IVA karena banyak ibu/WUS yang malu untuk periksa IVA. ${ }^{(7)}$ Penelitian lain menemukan faktor yang mempengaruhi keikutsertaan WUS dalam tes IVA adalah faktor pengetahuan. WUS dengan pengetahuan yang baik, memiliki kemungkinan untuk melakukan tes IVA sebesar 9,6 kali dibandingkan WUS dengan pengetahuan yang kurang baik. ${ }^{(8)}$

Berdasarkan uraian diatas, peneliti tertarik untuk mengetahui faktor-faktor yang berhubungan dengan keikutsertaan Wanita Usia Subur (WUS) dalam deteksi dini kanker serviks metode IVA di Puskesmas Kota Padang tahun 2018.

\section{METODE}

Penelitian ini merupakan penelitian explanatory dengan pendekatan cross sectional. Penelitian dilakukan dari bulan Februari hingga Oktober 2018 dengan jumlah sampel sebanyak 110 responden yang dipilih berdasarkan metode consecutive sampling yaitu sampel dipilih berdasarkan wanita usia subur menikah yang datang ke poli KIA/KB puskesmas 
untuk periksa atau berobat. Sedangkan besar sampel didapat dengan menggunakan rumus Slovin. Pengumpulan data dilakukan dengan wawancara oleh enumerator yang telah dilatih terlebih dahulu dan menggunakan pedoman kuesioner yang telah diuji validitas dan reliabilitasnya. Data dianalisis dengan uji Chi-square dan multiple regresi logistik dengan derajat kepercayaan 95\%. Informed consent diberikan kepada responden yang bersedia berpartisipasi dalam penelitian ini. ${ }^{(9)}$

\section{HASIL DAN PEMBAHASAN}

Tabel 1 menunjukkan bahwa Karakteristik responden kurang dari separuh $(44,6 \%)$ berumur diatas 40 tahun, sebagian besar tidak bekerja atau ibu rumah tangga $(79,1 \%)$. Lebih dari separuh responden tidak pernah tes IVA $(60,9 \%)$ dan hanya kurang dari separuhnya saja yang pernah tes IVA. Alasan mereka tidak tes IVA adalah tidak tahu proses tes IVA, ragu akan manfaatnya $(68,1 \%)$, takut dan malu untuk periksa $(18,1 \%)$, dan merasa tidak perlu untuk tes karena merasa sehat $(6 \%)$.

Tabel 1. Distribusi frekuensi WUS dalam deteksi dini kanker serviks metode IVA di Puskesmas Kota Padang Tahun 2018

\begin{tabular}{lcc}
\hline \multicolumn{1}{c}{ Variabel } & F & \% \\
\hline Keikutsertaan Deteksi Dini Metode IVA & 44 & 39,1 \\
Pernah & 66 & 60,9 \\
Tidak Pernah & 61 & 55,4 \\
\hline Umur & 49 & 44,5 \\
$\quad 40$ tahun & & \\
$\geq 40$ tahun & 23 & 20,9 \\
\hline Jenis Pekerjaan & 87 & 79,1 \\
Bekerja & & \\
Tidak bekerja & 48 & 43,6 \\
\hline Tingkat Pengetahuan & 62 & 56,4 \\
Baik & & 38,2 \\
Kurang & 42 & 61,8 \\
\hline Sikap & 68 & \\
Positif & & 92,7 \\
Negatif & 102 & 7,3 \\
\hline Keterjangkauan Jarak & 8 & 50 \\
Dekat & & 50 \\
Jauh & 55 & 32,7 \\
\hline Akses Informasi & 55 & 67,3 \\
Mendapatkan informasi & & \\
Tidak mendapatkan informasi & 36 & 74 \\
\hline Dukungan Suami & & \\
Mendukung & & \\
Tidak mendukung & & \\
\hline
\end{tabular}


Lebih dari separuh responden memiliki tingkat pengetahuan yang kurang mengenai kanker serviks dan deteksi dini kanker serviks dengan tes IVA $(56,4 \%)$, hal ini didukung dari hasil wawancara dengan bidan puskesmas bahwa penyuluhan tentang tes IVA belum sering dilakukan, hanya sekali saja pada saat ibu datang ke poli KIA sehingga masih banyak ibu yang belum yakin akan manfaatnya. Demikian juga 61,8\% responden bersikap negatif terhadap tes IVA $(61,8 \%)$, mereka berpendapat bahwa bila belum merasa ada kelainan, belum perlu tes IVA. Walaupun dalam hal jarak rumah responden dengan layanan tes IVA sebagian besar merasa dekat dengan puskesmas (89\%), tetapi sebagian besar suami mereka tidak mendukung untuk tes IVA $(67,3 \%)$ sehingga hal ini mempengaruhi keputusan WUS untuk melakukan tes.

Secara teori, tindakan mengikuti deteksi dini kanker serviks dengan tes IVA merupakan bagian dari perilaku yang mendukung kesehatan. Notoatmodjo mendefinisikan perilaku kesehatan sebagai perilaku atau usaha-usaha seseorang untuk memelihara atau menjaga kesehatan agar tidak sakit dan usaha untuk penyembuhan jika sakit. Dari hasil penelitian ini ditemukan bahwa rendahnya keikutsertaan WUS dalam deteksi dini kanker serviks dengan tes IVA dapat disebabkan karena tingkat pengetahuan WUS yang kurang yang akhirnya membentuk sikap negatif terhadap tes, didukung oleh faktor lingkungan terutama suami yang melarang mereka untuk tes. ${ }^{(10)}$

Menurut teori Green, reinforcing factor juga sebagai faktor penentu perilaku seseorang, terutama sikap lingkungan terdekat dalam hal ini suami sangat menentukan dalam bertindak tes IVA. ${ }^{(11)}$ Suami sebagai kepala keluarga dalam masyarakat patriakhal sangat berperan sebagai pengambil keputusan dalam kesehatan keluarga termasuk istri. Sehingga informasi tentang tes IVA tidak hanya para WUS yang perlu diberikan penyuluhan tentang IVA tetapi suami mereka juga perlu mendapatkan informasi yang benar sehingga mereka dapat memberikan dukungan kepada para istri untuk tes. ${ }^{(12)}$

Tabel 2 menunjukkan bahwa terdapat hubungan yang signifikan antara tingkat pengetahuan ( $p$ value 0,000), sikap ( $p$ value 0,041), akses informasi ( $p$ value 0,000), dan dukungan suami ( $p$ value 0,000) dengan keikutsertaan WUS dalam tes IVA. Sedangkan umur, jenis pekerjaan dan keterjangkauan jarak secara statistic tidak berhubungan dengan keikutsertaan WUS dalam tes IVA. 
Tabel 2. Faktor-faktor yang berhubungan dengan keikutsertaan WUS dalam tes IVA

\begin{tabular}{|c|c|c|c|c|c|c|c|c|}
\hline \multirow[t]{3}{*}{ Kategori } & \multicolumn{4}{|c|}{$\begin{array}{c}\text { Keikutsertaan Deteksi } \\
\text { Dini Kanker Serviks } \\
\text { Metode IVA }\end{array}$} & \multirow{2}{*}{\multicolumn{2}{|c|}{ Jumlah }} & \multirow[t]{3}{*}{ POR $(95 \%$ CI) } & \multirow[t]{3}{*}{$p$-value } \\
\hline & \multicolumn{2}{|c|}{$\begin{array}{l}\text { Tidak } \\
\text { Pernah }\end{array}$} & \multicolumn{2}{|c|}{ Pernah } & & & & \\
\hline & f & $\%$ & f & $\%$ & f & $\%$ & & \\
\hline \multicolumn{9}{|l|}{ Umur } \\
\hline$<40$ tahun & 37 & 60,73 & 24 & 39,3 & 49 & 100 & 0,9 & 1,000 \\
\hline$\geq 40$ tahun & 30 & 61,2 & 19 & 38,8 & 61 & 100 & $(0,4-2,1)$ & \\
\hline \multicolumn{9}{|l|}{ Jenis Pekerjaan } \\
\hline Bekerja & 12 & 52,2 & 11 & 47,8 & 23 & 100 & 1,5 & 0,468 \\
\hline Tidak Bekerja & 55 & 63,2 & 32 & 36,8 & 87 & 100 & $(0,6-3,9)$ & \\
\hline \multicolumn{9}{|l|}{$\begin{array}{l}\text { Tingkat } \\
\text { Pengetahuan }\end{array}$} \\
\hline Pengetahuan & & & & & & & & \\
\hline Baik & 14 & 29,2 & 34 & 70,8 & 48 & 100 & 14,3 & 0,000 \\
\hline Kurang & 53 & 85,5 & 9 & 14,5 & 62 & 100 & $(5,5-36,6)$ & \\
\hline \multicolumn{9}{|l|}{ Sikap } \\
\hline Positif & 20 & 47,6 & 22 & 52,4 & 42 & 100 & 2,4 & 0,041 \\
\hline Negatif & 47 & 69,1 & 21 & 30,9 & 68 & 100 & $(1,1-5,4)$ & \\
\hline \multicolumn{9}{|l|}{$\begin{array}{l}\text { Keterjangkauan } \\
\text { Jarak }\end{array}$} \\
\hline Terjangkau & 61 & 59,8 & 41 & 40,2 & 102 & 100 & 2,0 & 0,637 \\
\hline Tidak Terjangkau & 6 & 75 & 2 & 25 & 8 & 100 & $(0,3-10,4)$ & \\
\hline \multicolumn{9}{|l|}{ Akses Informasi } \\
\hline Baik & 15 & 27,3 & 40 & 72,7 & 55 & 100 & 46,2 & 0,000 \\
\hline Kurang Baik & 52 & 94,5 & 3 & 5,5 & 55 & 100 & $(12,5-170,6)$ & \\
\hline \multicolumn{9}{|l|}{ Dukungan } \\
\hline Baik & 5 & 13,9 & 31 & 86,1 & 36 & 100 & 32 & 0,000 \\
\hline Kurang & 62 & 83,8 & 12 & 16,2 & 74 & 100 & $(10,3-99,0)$ & \\
\hline
\end{tabular}

Tabulasi silang menunjukkan bahwa responden yang tidak tes IVA lebih banyak pada yang berumur lebih dari 40 tahun $(61,2 \%)$ dibanding yang <40 tahun, lebih banyak pada yang tidak bekerja $(63,2 \%)$, berpengetahuan kurang $(85,5 \%)$, bersikap negatif $(69,1 \%)$, merasa jauh dari layanan (75\%), kurang mendapatkan informasi $(94,5 \%)$ dan tidak mendapat dukungan suami $(84,8 \%)$. Dalam penelitian ini terdapat 2 kelompok umur, yaitu kelompok umur $<40$ tahun dan kelompok umur $\geq 40$ tahun. Usia 40 tahun dijadikan batasan karena prevalensi kanker serviks kebanyakan terjadi pada umur 40-50 tahun dan membutuhkan waktu sekitar 10 tahun bagi lesi pra kanker untuk berubah menjadi kanker serviks, sehingga deteksi dini perlu dilakukan 10 tahun lebih awal atau dalam umur $<40$ tahun. Semakin bertambah umur, seseorang semakin rentan terhadap penyakit kanker cervik, tetapi bila tingkat 
pengetahuan dan kematangan berpikir seseorang kurang baik dalam hal ini tentang kanker servik dan tes IVA maka akan sulit seseorang bertindak sesuai dengan anjuran.

Umur yang semakin dewasa seharusnya akan lebih mudah untuk beradaptasi dengan lingkungan sekitar sehingga bisa lebih memahami kebermanfaatan dalam mengikuti deteksi dini kanker serviks. ${ }^{(13)}$ Sebagian besar responden tidak bekerja yaitu sebesar $79,1 \%$ dan hanya 20,9\% yang bekerja. Pekerjaan adalah aktifitas yang dilakukan seseorang dengan rutin yang menghasilkan uang dalam rangka memenuhi kebutuhan ekonominya. Pekerjaan sangat mempengaruhi tingkat perekonomian seseorang.

Menurut Notoatmodjo (2003) adanya pekerjaan akan menyebabkan seseorang meluangkan banyak waktu dan tenaga untuk menyelesaikan pekerjaan yang dianggap penting sehingga cenderung mempunyai banyak waktu untuk tukar pendapat/pengalaman antar teman di tempat kerjanya. ${ }^{(10)}$ Lingkungan pekerjaan memungkinkan WUS mendapat informasi mengenai deteksi dini kanker serviks dengan tes IVA. Pekerjaan juga dikaitkan dengan daya beli sehingga wanita yang bekerja akan semakin mandiri dan semakin mudah untuk memeriksakan kesehatannya. ${ }^{(14)}$

\section{Tingkat Pengetahuan Responden tentang Tes IVA}

Hasil penelitian menunjukkan bahwa lebih separuh responden memiliki pengetahuan kurang baik $(56,4 \%)$ mengenai kanker serviks dan deteksi dini kanker serviks metode IVA. Hasil ini sejalan dengan penelitian yang dilakukan Eva Sulistiyowati bahwa lebih banyak responden dengan tingkat pengetahuan kurang baik $(77,8 \%)$ mengenai kanker serviks dan deteksi dini kanker serviks metode IVA. Kurangnya pengetahuan WUS terlihat dari responden yang tidak paham tentang tahapan pemeriksaan IVA sebesar 83,6\%, mereka tidak mengerti faktor penyebab wanita mudah terkena kanker serviks sebesar 66,4\%, dan pengertian kanker serviks sebesar 58,2\%. Demikian juga responden yang tidak tau tentang puskesmas menyediakan layanan IVA sebesar 54,5\%. Hal ini menunjukkan bahwa promosi kesehatan mengenai kanker serviks dan deteksi dini kanker serviks metode IVA masih belum diberikan secara optimal, hanya $45,5 \%$ responden saja yang mengetahui bahwa puskesmas menyediakan layanan deteksi dini kanker serviks metode IVA. ${ }^{(15)}$

Pengetahuan merupakan hasil dari tahu, dan terjadi setelah orang melakukan penginderaan terhadap suatu objek tertentu. Penginderaan terjadi melalui pancaindra manusia, yakni indra 
penglihatan, pendengaran, penciuman, rasa, dan raba. Green memaparkan bahwa pengetahuan tertentu tentang kesehatan mungkin penting sebelum tindakan kesehatan pribadi terjadi, namun tindakan kesehatan yang diharapkan tidak akan terwujud kecuali seseorang mendapat dorongan yang kuat dari diri sendiri yang membuat ia bertindak atas dasar ilmu pengetahuan yang dimilikinya. Pengetahuan menjadi faktor yang penting namun tidak cukup memadai dalam membentuk perubahan perilaku kesehatan seseorang. ${ }^{(11)}$ Dalam upaya peningkatan tingkat pengetahuan WUS perlu dilakukan penyuluhan rutin mengenai kanker serviks dan deteksi dini kanker serviks metode IVA agar WUS dan masyarakat luas lebih mengenal dengan baik mengenai kanker serviks dan deteksi dini kanker serviks metode IVA.

Berdasarkan uji statistik diperoleh nilai p-value $<0,05$ maka dapat disimpulkan bahwa terdapat hubungan yang signifikan antara tingkat pengetahuan dengan keikutsertaan WUS dalam deteksi dini kanker serviks metode IVA. Hasil ini sejalan dengan penelitian yang dilakukan Eva Sulistiyowati bahwa terdapat hubungan yang signifikan antara pengetahuan dengan keikutsertaan WUS dalam deteksi dini kanker serviks metode IVA. ${ }^{(15)}$ Hal ini dapat dikarenakan tingkat pengetahuan merupakan faktor predisposisi yang mempermudah atau mendisposisi terjadinya perilaku kesehatan seseorang yaitu keikutsertaan dalam deteksi dini kanker serviks metode IVA.

\section{Sikap terhadap Tes IVA}

Hasil penelitian menunjukkan bahwa sebagian besar responden memiliki sikap negatif $(61,8 \%)$. Artinya, lebih banyak responden dengan sikap negatif dibandingkan responden dengan sikap positif. Hal ini sejalan dengan penelitian yang dilakukan Ni Made bahwa sebagian besar responden memiliki sikap negatif.

Berdasarkan uji statistik diperoleh nilai $p$-value $<0,05$ maka dapat disimpulkan bahwa terdapat hubungan yang signifikan antara sikap dengan keikutsertaan WUS dalam deteksi dini kanker serviks dengan tes IVA. Hasil ini sejalan dengan penelitian Ni Made Sri Dewi L, dkk (2013) bahwa terdapat hubungan yang signifikan antara sikap dengan keikutsertaan WUS dalam deteksi dini kanker serviks metode IVA. Hal ini disebabkan karena sikap merupakan reaksi atau respon yang masih tertutup dari seseorang terhadap suatu stimulus atau objek. Manifestasi sikap itu tidak dapat langsung dilihat, tetapi hanya dapat ditafsirkan terlebih dahulu dari perilaku yang tertutup. WUS tidak hanya harus cukup dengan memiliki tingkat pengetahuan yang baik saja mengenai 
deteksi dini kanker serviks metode IVA, namun juga harus tercerminkan dalam sikap. WUS dengan sikap positif akan mempengaruhi keinginan WUS untuk mau melakukan deteksi dini kanker serviks metode IVA. $^{(13)}$

\section{Keterjangkauan Jarak Layanan Tes IVA}

Hasil penelitian menunjukkan bahwa sebagian besar responden memiliki jarak rumah yang dekat dengan Puskesmas $(92,7 \%)$. Hasil ini sejalan dengan penelitian J.Melorose bahwa sebagian besar responden memiliki jarak rumah yang dekat/terjangkau dengan puskesmas $(82,4 \%)$. Jarak adalah rentang yang harus ditempuh seseorang dari suatu tempat ke tempat yang dituju. Jarak sangat mempengaruhi seseorang untuk melakukan tindakan kesehatan. Semakin dekat jarak maka semakin mendukung seseorang untuk bisa melakukan kunjungan ke pelayanan kesehatan dan sebaliknya, semakin jauh jarak semakin menjadi hambatan bagi sesorang untuk melakukan kunjungan ke pelayanan kesehatan. Dalam upaya penjangkauan WUS di berbagai bagian wilayah perlu dilakukan peningkatan koordinasi antara puskesmas wilayah dengan puskesmas pembantu atau kader kesehatan. $^{(16)}$

Berdasarkan uji statistik diperoleh nilai $\mathrm{p}$-value $>0,05(\mathrm{p}=0,637)$ maka dapat disimpulkan bahwa tidak terdapat hubungan yang signifikan antara keterjangkauan jarak dengan keikutsertaan WUS dalam tes IVA. Hasil ini tidak sejalan dengan penelitian Nurhasanah, dkk (2016) dan Siska H (2017) bahwa terdapat hubungan yang signifikan antara jarak dengan keikutsertaan WUS dalam deteksi dini kanker serviks. Menurut teori L. Green faktor keterjangkauan jarak merupakan faktor pemungkin yang memungkinkan seseorang untuk melakukan tindakan kesehatan dan menjangkau pelayanan kesehatan. Tidak terbuktinya hipotesis penelitian dalam hal ini dapat disebabkan karena meskipun memiliki jarak rumah jauh, WUS dapat mengakses informasi mengenai kanker serviks dan deteksi dini kanker serviks metode IVA melalui internet sehingga mempengaruhi kunjungan WUS ke Puskesmas untuk melakukan deteksi dini kanker serviks metode IVA.

\section{Akses Informasi tentang Kanker Serviks dan Tes IVA dari Puskesmas}

Hasil penelitian menunjukkan terdapat hubungan yang signifikan antara akses informasi dengan keikutsertaan WUS dalam deteksi dini kanker serviks metode IVA dengan nilai $p$ value 0,000. Separuh responden tidak memperoleh informasi mengenai kanker serviks dan deteksi dini kanker serviks metode IVA 
(50\%). Hal ini karena belum semua masyarakat terutama WUS mendapatkan informasi tentang bahaya kanker servik dan tes deteksi dini kanker. Kurangnya informasi ini dari puskesmas membuat masyarakat kurang memahami dan kurang peduli terhadap bahaya kanker servik yang dapat dicegah sejak dini. Selain itu masyarakat yang tidak faham menjadi mudah takut akan tesnya dan cenderung menghindar untuk tes.

Kemudahan akses informasi akan memungkinkan terwujudnya perubahan perilaku kesehatan khususnya pelaksanaan deteksi dini kanker serviks. Akses informasi dapat diperoleh melalui media elektronik, media cetak, internet, dan sebagainya. Informasi juga dapat diterima melalui petugas langsung dalam bentuk penyuluhan, melalui siaran dikelompokkelompok, dan melalui media massa. ${ }^{(17)(18)}$ Menurut Green (2005) mudah atau sulitnya akses informasi tentang kesehatan menentukan tingkat pengetahuan dan sikap yang akhirnya membentuk perilaku masyarakat. Untuk meningkatkan akses informasi yang diterima WUS selain dilakukan melalui media cetak dan media elektronik juga dapat lebih maksimal dengan melakukan penyuluhan baik secara formal (sosialisasi) ataupun informal (seperti arisan, kelompok pengajian ibuibu). Perlu dilakukan intensitas sosialisasi mengenai kanker serviks dan deteksi dini kanker serviks dengan metode IVA oleh stakeholder sehingga meningkatkan akses informasi masyarakat. ${ }^{(19)}$

\section{Dukungan Suami}

Hasil penelitian menunjukkan bahwa sebagian besar suami tidak memberikan dukungan kepada WUS untuk mengikuti deteksi dini kanker serviks melalui tes IVA $(67,3 \%)$. Terdapat hubungan yang signifikan antara dukungan suami dengan keikutsertaan WUS dalam tes IVA dengan nilai $p$-value $<0,05$ ( $p$ value 0,000 ) Hasil ini sesuai dengan penelitian Wahyuni. Hal ini ditunjukkan dengan tidak adanya partisipasi suami untuk menemani istri melakukan tes IVA sebesar $88,2 \%$. $^{(20)}$ Masih banyaknya suami yang melarang tes IVA.

Suami yang merupakan bagian dari keluarga yang memiliki pemahaman baik mengenai perilaku sehat akan memberikan dukungan kepada istri. Dukungan suami dapat memberikan keuntungan emosional yaitu memberikan rasa nyaman dan memberikan semangat bagi individu untuk melaksanakan tindakan kesehatan. Oleh karena itu peran suami sangat penting terhadap tindakan individu khususnya dalam tindakan deteksi dini kanker serviks.

Untuk meningkatkan dukungan suami, maka dapat dilakukan dengan memberikan brosur/leaflet kepada WUS agar nantinya bisa diberikan kepada 
pria/suami serta menjadikan suami WUS sebagai sasaran penyuluhan tentang pentingnya deteksi dini kanker serviks metode IVA.

Tabel 3. Model akhir analisis multivariat pengaruh tingkat pengetahuan, akses informasi dan dukungan suami terhadap partisipasi WUS dalam tes IVA

\begin{tabular}{lcccc}
\hline \multicolumn{1}{c}{ Variabel } & p-value & POR & Lower & Upper \\
\hline Tingkat Pengetahuan & 0,002 & 14,770 & 2,665 & 81,866 \\
\hline Akses Informasi & 0,000 & 29,443 & 4,584 & 189,121 \\
\hline Dukungan Suami & 0,000 & 46,693 & 6,803 & 320,462 \\
\hline
\end{tabular}

Tabel 3 menunjukkan bahwa dukungan suami merupakan variabel yang paling berpengaruh terhadap keikutsertaan WUS dalam tes IVA di dengan nilai $p$ value 0,000 dan Odds Ratio sebesar 46,6 yang artinya WUS yang mendapatkan dukungan suami mempunyai kemungkinan 46 kali melakukan tes IVA dibandingkan dengan WUS yang tidak didukung suami untuk tes IVA setelah variabel lain dikontrol.

Faktor budaya patriachal menjadikan wanita lebih patuh dan mau mendengarkan pendapat suami sebagai pemimpin rumah tangga dan sebagai pengambil keputusan. Hal ini menjadikan dukungan suami merupakan faktor yang dominan dalam mempengaruhi keikutsertaan WUS dalam deteksi dini kanker serviks metode IVA.

\section{SIMPULAN}

Tingkat pengetahuan, sikap, akses informasi, dan dukungan suami berhubungan dengan keikutsertaan WUS dalam deteksi dini kanker serviks metode
IVA di Puskesmas Kota Padang tahun 2018. Dukungan suami merupakan faktor yang paling dominan mempengaruhi keikutsertaan WUS dalam deteksi dini kanker serviks metode IVA. Disarankan kepada pihak Puskesmas dalam hal ini bidan untuk meningkatkan promosi kesehatan yang dilakukan secara rutin dan intensif mengenai kanker serviks dan deteksi dini kanker serviks metode IVA kepada WUS dan memperluas sasaran promosi kesehatan kepada para pria dan suami WUS agar mereka dapat mendukung dan memotivasi pasangannya untuk melakukan deteksi dini kanker serviks melalui tes IVA.

\section{KEPUSTAKAAN}

1. Astrid S. Kupas Tuntas Kanker Payudara Leher Rahim \& Rahim. Yogyakarta: Penerbit Pustaka Baru Press; 2015.

2. Globocan. No Title. Cervical Cancer, Estimate Incidence, Mortality and Prevalence 
Worldwide in 2012. 2012.

3. Kementerian Kesehatan Republik Indonesia. Profil Kesehatan Indonesia Tahun 2015. Jakarta: Kementerian Kesehatan RI; 2015.

4. DKK Padang. Profil Kesehatan Kota Padang Tahun 2017. Padang: Dinas Kesehatan Kota Padang; 2017.

5. Soebrachman A. Awas. 7 Kanker Paling Mematikan. Yogyakarta: Syura Media Utama; 2011.

6. Kepmenkes RI. Kepmenkes RI Nomor 796/MENKES/SK/VII/2010 tentang Pedoman Kanker Payudara dan Kanker Leher Rahim. Jakarta: Kemenkes RI; 2010.

7. Juanda D, Kesuma H. Pemeriksaan Metode IVA ( Inspeksi Visual Asam Asetat ) untuk Pencegahan Kanker Serviks. Jurnal Kedokteran dan Kesehatan. 2015;

8. Fauziah RM, Wirawan JP, Lorianto R, Utari AP, Cahyanur R, Budiningsih S. Deteksi Dini Kanker Serviks pada Pusat Pelayanan Primer di Lima Wilayah DKI Jakarta. Journal Indonesia Medica Assoc. 2011;

9. Saryono. Metodologi Penelitian Kualitatif dan Kuantitatif dalam Bidang Kesehatan. Yogyakarta: Nuha Medika; 2013.

10. Sukidjo N. Pendidikan dan Perilaku Kesehatan. Jakarta: Rineka Cipta;
2003.

11. Green L., Kreuter MW. Health Program Planning: An Educational and Ecological Approach. 4th ed. New York: McGraw-Hill Higher Education; 2005.

12. Febriani CA. Faktor-faktor yang Berhubungan dengan Deteksi Dini Kanker Leher Rahim di Kecamatan Gisting Kabupaten Tanggamus Lampung. Jurnal Kesehatan. 2016;

13. Suryani N, Murdani P. Hubungan Tingkat Pengetahuan dan Sikap Wanita Usia Subur (WUS) dengan Pemeriksaan Inspeksi Visual Asam Asetat (IVA) di Puskesmas Buleleng I. Jurnal Magister Kedokteran Keluarga. 2013;

14. Pradono J, Sulistiowati Ni. Hubungan antara Tingkat Pendidikan, Pengetahuan tentang Kesehatan Lingkungan, Perilaku Hidup Sehat dengan Status Kesehatan Studi Korelasi pada Penduduk Umur 10 - 24 Tahun di Jakarta Pusat. Buletin Penelitian Sistem Kesehatan. 2014;17(1):8995.

15. Sulistiowati E, Sirait AM, Teknologi P, Kesehatan T, Klinik DE, Kesehatan I, et al. Pengetahuan Tentang Faktor Risiko, Perilaku dan Deteksi Dini Kanker Serviks Dengan Inspeksi Visual Asam 
Asetat (IVA) pada Wanita di

Kecamatan Bogor Tengah, Kota

Bogor. Buletin Penelitian

Kesehatan. 2014;

16. Melorose J, Perroy R, Careas S.

Faktor-Faktor yang Berhubungan

Dengan Perilaku PUS dalam

Deteksi Dini Kanker Serviks dengan

Metode IVA di Wilayah Kerja

Puskesmas Kebumen I Kabupaten

Kebumen. Statew Agric L Use

Baseline 2015. 2015;

17. Yuliwati. Faktor-faktor yang

Berhubungan dengan Perilaku WUS

dalam Deteksi Dini Kanker Leher

Rahim Metode IVA di Wilayah

Puskesmas Prembun, Kabupaten

Kebumen Tahun 2012. Depok:

Universitas Indonesia; 2012.
18. AUN L, T. ME and A. Pengaruh Media Leaflet dan Film Terhadap Pengetahuan tentang Kanker Serviks dan Partisipasi Wanita dalam Deteksi Dini Kanker Serviks di Kampung Darek Kecamatan Padangsidempuan Selatan Tahun 2015. 2017;11.

19. Basuki D, Puspitasari A. Hasil Skrining Metode Pemeriksaan Inspeksi Visual Asam Asetat (IVA) Pada Wanita Usia Subur di Puskesmas Blooto. Jurnal Keperawatan. 2014;

20. Wahyuni NS. Faktor-Faktor yang Mempengaruhi Perilaku Deteksi Dini Kanker Serviks di Kecamatan Ngampel Kabupaten Kendal Jawa Tengah. Jurnal Keperawatan Maternal. 2013; 